\title{
Ocean Electric Field Tests of Carbon Fiber Electrodes Prepared by Nitric Acid Oxidation
}

\author{
Yusu SONG, Hongxia LI, Yueming WANG* \\ Key Laboratory of Chemistry and Materials, Institute of Basic Education, Naval University of Engineering, WuHan, 430033, \\ P.R China \\ crossref http://dx.doi.org/10.5755/j02.ms.20907
}

Received 08 June 2018; accepted 06 May 2019

\begin{abstract}
The concentrated nitric acid oxidation was chosen as the surface treatments on carbon fibers in this paper. Treated carbon fibers were subjected to subsequent processing and forming, the electrodes applied in marine electric field detection were prepared. The electrochemical properties that related to practical application in marine electric field detection such as potential stability, polarization and cyclic voltammetry performance, the electrochemical impedance and the self-noise were characterized, thus an electrochemical evaluation system was formed to optimize the oxidation technology. Combining with the TGA and FTIR, the physical properties of carbon fibers were characterized and some oxidation laws were induced. The results indicate that the carbon fiber electrode prepared by oxidation 4 hours at $110{ }^{\circ} \mathrm{C}$ has the best electrochemical performance for detection.

Keywords: marine field detection, carbon fiber electrode, electrochemistry, carbon fiber, electrode.
\end{abstract}

\section{INTRODUCTION}

Because of the feature of diverse origins, the ocean electric field, which could be induced by the ocean current, tides or the corrosion current of ships and other marine industrial equipment, has received much attention and been widely used in the resource exploration, marine geophysical analysis and the target position.

The detection is achieved through measuring the changing voltage between a pair of electrodes which have a fixed distance in the ocean. When a pair of electrodes are submerged in sea water, there must be an unknown but inherent voltage between them. Thus, a stable self-potential difference of these two electrodes in the sea water is the primary basis and its fluctuation would influence the detection accuracy.

The $\mathrm{Ag}-\mathrm{AgCl}$ electrode is the detection electrode used most frequently in this area, which is defined as a "resistive" electrode, for it has a reversible electrochemical reaction with the sea water:

$\mathrm{AgCl}+\mathrm{e} \leftrightarrow \mathrm{Ag}+\mathrm{Cl}^{-}$.

And the polarization effect, which is the main origin of self-potential fluctuation, can be decreased by this reaction, for accumulated charges on the surface can be assumed.

Another feasible electrode material is the carbon fiber [1], which is flexible and easy in shaping. Contrast to the $\mathrm{Ag}-\mathrm{AgCl}$ electrode, the carbon fiber electrode defined as a "capacitive" electrode, is chemical inert and similar to a capacitor for its relatively strong polarization effect with accumulated charges cannot be consumed. It's reported that such graphite electrode is more suitable for measurements of rapidly varying flows such as turbulence [1], because the influence brought by polarization effect could be weakened under such situations.
The carbon fiber electrodes (CFEs) accomplish the ocean electric field detection depend on their polarity and the presence of oxygen surface complexes are shown to improve their performances in sea water environment. The homogeneity between electrode pairs can be improved through surface treatment at the same time, which is propitious to practical use in pairs. When carbon material surfaces are treated with oxidizing gases or oxidizing acid solutions, such as nitric acid, oxygen functional groups will produce. And the variety and amount of them owe to different surface treatments, which commonly include electrochemical methods, chemical liquid-phase oxidation, plasma treatment and heat treatment [2-5].

In the present work, carbon fiber detection electrodes were focused and modified with nitric acid. The surface oxides are characterized by the FTIR method combined with thermo-gravimetric analysis (TGA), and the internal relationship of electrochemical performances were studied as well.

\section{MATERIALS AND METHODS}

\subsection{Pretreatments}

Carbon fiber, (CF, Toray, Japan), was used as the electrode material. To avoid any intrusion of sizing agents and surface contaminants, carbon fibers were ultrasonic cleaned in the acetone solution for $30 \mathrm{~min}$ before oxidation.

\subsection{Oxidation processes}

Concentrated nitric acid was used in the oxidation treatment of $\mathrm{CF}$. The modification was initiated by immersing the pretreated $\mathrm{CF}$ in $65 \%$ nitric acid solution. The process was performed at $110^{\circ} \mathrm{C}$ for $2 \mathrm{~h}, 4 \mathrm{~h}, 6 \mathrm{~h}$ respectively. After nitric acid treatment, the carbon fibers

\footnotetext{
${ }^{*}$ Corresponding author. Tel.: +86-15927668584.

E-mail address: lightbrave@163.com (Y. Wang)
} 
were leached by distilled water until the $\mathrm{pH}$ of filtrate water was above 6 , then dried for use.

\subsection{Electrode modelling}

The CF samples were tightly connected to wires in the form of a bundle. The junction was potted with epoxy resin totally to prevent water penetration. The carbon fiber electrode that oxidized for $2 \mathrm{~h}$ (CFEs-2), $4 \mathrm{~h}$ (CFEs-4), and $6 \mathrm{~h}$ (CFEs-6) were completely prepared, the untreated pairs (CFEs-0) were as the comparison.

\section{CHARACTERIZATION}

\subsection{Physical characterization of the carbon fibers}

FT-IR spectra was recorded on the spectrometer (Is 50 FR-IR Japan) in the $400 \sim 4000 \mathrm{~cm}^{-1}$ wavenumber range. 128 scans were taken at a resolution of $4 \mathrm{~cm}^{-1}$. The carbon fibers were first ground to powder in an agate mortar and then mixed with KBR at a mass ratio of 1:500. The mixture was press to discs of $10 \mathrm{~mm}$ in diameter at $10 \mathrm{MPa}$ for 5 min. TGA experiments were carried out with METTLER thermo-gravimetric analyzer. Carbon fiber samples of about $10 \mathrm{mg}$ were heated under a nitrogen stream of $2.0 \mathrm{~L} / \mathrm{h}$. The heating rate was $10^{\circ} \mathrm{C} / \mathrm{min}$, the temperature range was $100 \sim 900{ }^{\circ} \mathrm{C}$, above which the carbon fiber would fracture.

\subsection{Electrochemical characterization measurements}

The electrodes used in marine electric field detection are supposed to have stable electric potential difference between pairs, specific linearity, reversibility and sensibility, as well as a low self-noise level. Thus a related electrochemical evaluation system was formed to estimate the electrode performances for ensuring the feasibility and optimize the oxidation preparation technology, which mainly included the potential stability, polarization, cyclic voltammetry performance, electrochemical impedance performance and the self-noise level. All electrochemical measurements were carried out in $3.5 \% \mathrm{NaCl}$ solution at ambient temperature. The potential stability and self-noise level were measured using open circuit in the two-electrode system, the others used a three-electrode system, where the $\mathrm{Ag}-\mathrm{AgCl}$ electrode was used as the reference electrode, the $\mathrm{Ti}$ electrode as the counter electrode and the prepared carbon fiber as the working electrode. The sweep scan rate of polarization and cyclic voltammetry measurement was $5 \mathrm{mV} / \mathrm{s}$, within the potential ranged from $-200 \sim 200 \mathrm{mV}$ of the equilibrium potential, and measurement were accomplished through an electrochemical workstation (Zahner Germany). The self-noise level was measured by a noise evaluation system, which includes a potential amplification system (Sa400F3 amplifier and HB815 amplifier) and a data acquisition system. The self-noise of the whole system was lower than $2 \mathrm{nV}$.

\section{RESULTS AND DISCUSSION}

\subsection{FT-IR spectra of carbon fibers}

Fig. 1 shows the FT-IR spectra of carbon fiber samples. Samples had absorption bands at around $3443 \mathrm{~cm}^{-1}$,
$1631 \mathrm{~cm}^{-1}$ and $1384 \mathrm{~cm}^{-1}$. Compared with the standard absorption peak [3,6-9], the one at $3443 \mathrm{~cm}^{-1}$ could be assigned to the $-\mathrm{OH}$ stretching vibration, the one at $1384 \mathrm{~cm}^{-1}$ could be assigned to the $\mathrm{C}-\mathrm{O}$ stretching vibration of carboxylic groups. The one near $1631 \mathrm{~cm}^{-1}$ owes to the $\mathrm{C}=\mathrm{O}$ stretching vibration, which easily migrates to a lower wave number for the hydrogen bond on hydroxyl.

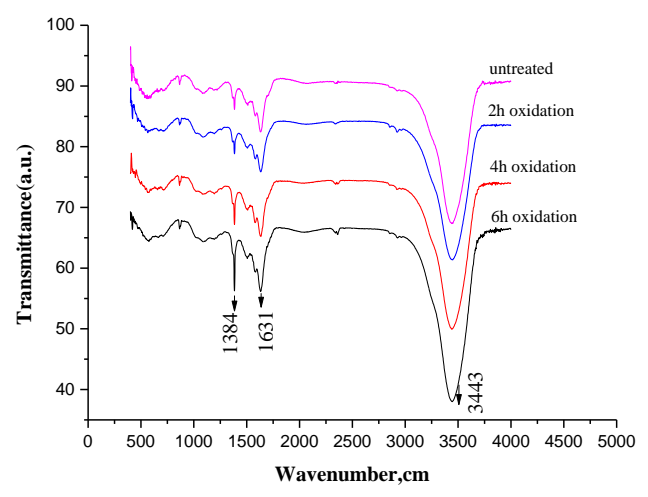

Fig. 1. The FI-IR spectra of carbon fibers in the range of $4000-400 \mathrm{~cm}^{-1}$

The $\mathrm{C}=\mathrm{O}$ and $\mathrm{C}-\mathrm{O}$ stretching vibration of the untreated carbon fiber mainly due to its original groups or the residual sizing agent. With the prolonged oxidation time, the $1631 \mathrm{~cm}^{-1}$ and $1384 \mathrm{~cm}^{-1}$ bands remained more visible. They indicate the formation of more carboxylic groups.

Trace oxygen-containing groups on the carbon fiber surface that generated during the industrial production, such as hydroxyl, phenolic hydroxyl, carbonyl, completely oxidized into carboxyl group with the oxidation time, resulting in the enhancement of absorption peak of $\mathrm{C}=\mathrm{O}$ and $\mathrm{C}-\mathrm{O}$ bond on carboxyl. Moreover, the defect sites on carbon fibers increased, which were easily to generate a lot of new hydroxyls under chemical attack, and these produced groups gradually transformed to higher activity ones, leading to the ultimate increase of carboxyl groups as well.

\subsection{Thermo-gravimetric analysis (TGA)}

The results of thermo-gravimetric analysis (TGA) for electrode samples are shown in Fig. 2.

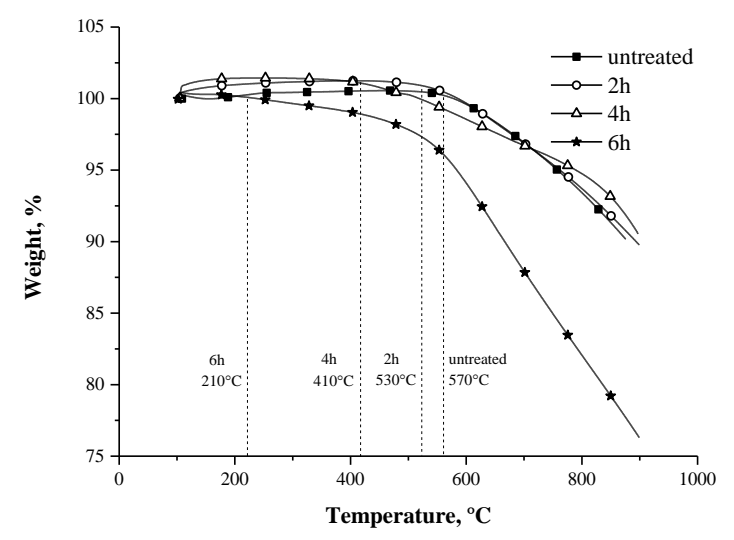

Fig. 2. The TGA curves of carbon fibers under different oxidation time at $110{ }^{\circ} \mathrm{C}$ 
The results of thermal gravimetric analysis (Fig. 2) show that, when the oxidation time increases, the decomposition temperature of the treated carbon fiber decreases gradually. From the point of view of the stability of carbon fiber structure, with the enhancement of oxidation degree, a large number of active oxygen-containing groups were generated on the carbon fiber surface, meanwhile the number of surface activated sites and the carbon atoms of defects increased. These positions became the most easily broken places and resulted in the decrease of fiber strength, destroying the fiber and lowering the thermal decomposition temperature.

The results of thermo-gravimetric analysis can also be explained by thermal decomposition of oxygen-containing functional groups formed on the surface of carbon fibers. In some papers [6-11], TPD technology was used to quantitatively analyze the oxygen containing groups of carbon fibers. In this technique, the surface functional groups would arise thermal decomposition at different temperatures in an inert atmosphere, escaping in the form of $\mathrm{CO}$ or $\mathrm{CO}_{2}$ which could be used to define the oxygen group and its quantity. Most of the carbon surface functional groups containing oxygen has a different decomposition temperature range.

In combination with references $[6-11]$, the decomposition temperature law of oxygen-containing functional groups on the surface of carbon materials can be obtained:

1. The decomposition temperature of carboxyl is the lowest, about $300 \sim 400{ }^{\circ} \mathrm{C}$ and even lower. Besides, carboxyl groups are acidic ones, the more acidic (for example, the effect of branched chain, the unsaturated carbon atom number in branches will influence the acid), the lower the decomposition temperature, the decomposition may occur at about $100{ }^{\circ} \mathrm{C}$.

2. The decomposition temperature of the anhydride formed by the dehydration of the adjacent carboxyl group is inferior to that of the carboxyl group, and decomposes at about $460{ }^{\circ} \mathrm{C}$.

3. At about $600{ }^{\circ} \mathrm{C}$, the order of decomposition is hydroxyl, phenol, ether, ester and carbonyl group.

4. The decomposition of carbonyl group and quinone are at $700 \sim 950{ }^{\circ} \mathrm{C}$. The weight loss in $800^{\circ} \mathrm{C}$ is mainly due to the decomposition of carbonyl group $\left(672 \sim 797^{\circ} \mathrm{C}\right)$, and the decomposition temperature of quinone is higher than $850{ }^{\circ} \mathrm{C}$.

The weightlessness of untreated carbon fibers was mainly due to residuary surface sizing agents which had poor thermal stability. It can be seen from the thermogravimetric curve that the weight loss of the oxidized $2 \mathrm{~h}$ carbon fiber is about $530^{\circ} \mathrm{C}$, which may be due to the initiation of new hydroxyl groups on the surface of carbon fiber. The CFEs-4 showed a significant weight loss at about $400{ }^{\circ} \mathrm{C}$, corresponding to the decomposition temperature of carboxyl group, indicating that the phenolic hydroxyl group of the surface were gradually oxidized to carboxyl group and transformed into high activity ones. The CFEs-6 continued to lose weight from $200{ }^{\circ} \mathrm{C}$, corresponding to the more acidic carboxyl structure, that was to say, the carboxyl group which in the branched structure and with more unsaturated carbon atoms increased.
This means that the carbon fiber surface has a large of carboxyl which is the worst in thermal stability, with the prolonged oxidation time, the carbon chain is broken, the carbon atom defects increase, accordingly the branched chain increased. From the point of view of oxygencontaining functional groups, the branching structure and carboxyl structure of CFEs-6 are certainly richer, which is consistent with the FT-IR results.

\subsection{Stability of electric potential differences}

Fig. 3 shows the potential difference change of the electrode pair versus time after immersing into the sea water. It is seen that CFEs-4 take the shortest time to reach a relative stable potential, then CFEs-2, CFEs-0, CFEs-6 follow, and CFEs-0 have the largest amplitude of variation.

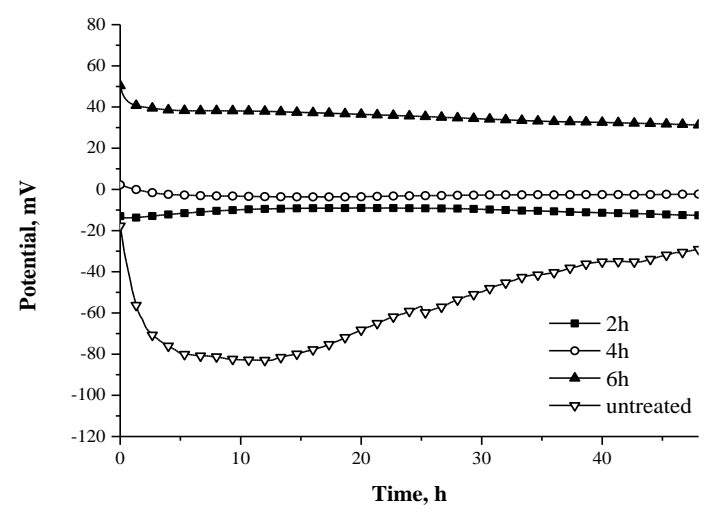

Fig. 3. The potential variation of electrode pairs after into the sea water 48 hours

Though the fast stability always meant rapid deployment, more precisely, the potential drift must be considered. After merged in seawater for two days, potential fluctuations of electrode pairs were recorded in the Table 1. Contrast to relatively fast to reach the stability, CFEs- 2 had an unobvious potential fluctuations, which was similar to the untreated ones. Therefore, it was more suitable to consider that CFEs-2 reached a relative stability compared with the very beginning, they were still accompanied with a potential drift, which largely influence the accuracy of measurements.

Table. 1. The potential stability and drift of electrode pairs

\begin{tabular}{|c|c|c|}
\hline $\begin{array}{c}\text { The oxidation } \\
\text { time }\end{array}$ & $\begin{array}{c}\text { The time to reach } \\
\text { stability, } \mathrm{h}\end{array}$ & $\begin{array}{c}\text { The potential } \\
\text { drifts, } \mathrm{mV} / \mathrm{d}\end{array}$ \\
\hline Untreated & 72 & 30 \\
\hline $2 \mathrm{~h}$ & 2 & 3.456 \\
\hline $4 \mathrm{~h}$ & 2 & 0.84 \\
\hline $6 \mathrm{~h}$ & 96 & 4.392 \\
\hline
\end{tabular}

When the surface polar functional groups cannot reach a close physical adsorption with ions in the sea water, such as the untreated CFs and CFEs-2 which had poor polar functional groups, the potential fluctuations will occur, thus failing to measure weak marine electric field. The structure of CFEs-6 was seriously damaged and had many defects with high energy. It was too active to establish a stable electric double layer structure, and the electrode potential was difficult to be stable. Proper treatment can improve the polarity of the carbon fiber surface, making the interface 
between the electrode and sea water quickly establish a stable electric double layer. Thus, the CFEs-4 can not only achieve the rapid deployment of practical requirements, but also keep good stability.

\subsection{Polarization and cyclic voltammetry}

The linearity is an important indicator of the selection of electrodes, for the current flowing through the electric field electrode should have a linear relationship with the applied voltage, which ultimately affects the accuracy of the detection.

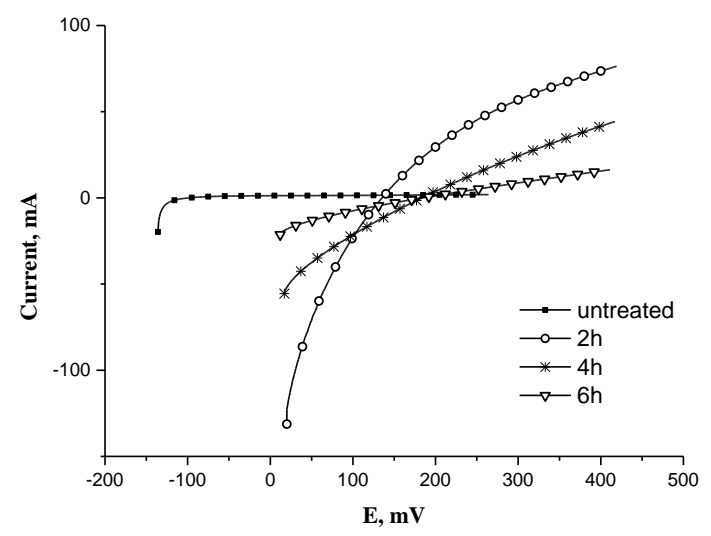

Fig. 4. The polarization of carbon fiber electrodes

The position movement of the curve in the graph was due to the change of the balance potential of the electrode. The linearity results are listed in Table 2 the lower figure of linearity means better linearity. The result indicates that only CFEs- 4 and CFEs- 6 have better linearity to cover the basic requirements for sensor electrodes. In particular, the untreated carbon fiber electrode shows obvious electron accumulation on the surface.

Table. 2. The polarization curve linearity of carbon fiber electrodes

\begin{tabular}{|c|c|c|c|c|}
\hline & untreated & $\begin{array}{c}2 \mathrm{~h} \\
\text { oxidation }\end{array}$ & $\begin{array}{c}4 \mathrm{~h} \\
\text { oxidation }\end{array}$ & $\begin{array}{c}6 \mathrm{~h} \\
\text { oxidation }\end{array}$ \\
\hline Linearity & 5.608 & 1.2968 & 0.138 & 0.150 \\
\hline
\end{tabular}

It is easy to see that linear polarization curves demonstrate two kinds of electrodes, the capacitive or resistive ones. Because of accumulated charges initiated by polarization effects, the curve of capacitive ones is to be an arc. The better the linearity, the less capacitive of electrodes. CFEs-0 and CFEs-2 are evidently more capacitive electrodes, contrarily, CFEs- 4 and CFEs- 6 are resistive. The linear slope means linear resistance to some extent and CFEs-6 has a larger resistance, which is correspond to the EIS result in the next section.

The capacitive or resistive feature also reflect in cyclic voltammetry curves. Fig. 5 shows a typical capacitor, the area enclosed by the curve is to be a rectangle. After oxidation, the capacitive effect weakened and the reversibility of the electrode was better.

\subsection{Electrochemical impedance spectroscopy (EIS)}

It can be seen from figure Fig. 6 a that the impedance of $2 \mathrm{~h}$ carbon fiber electrode is the smallest, due to the oxidation of impurities on the surface and little oxygencontaining groups.

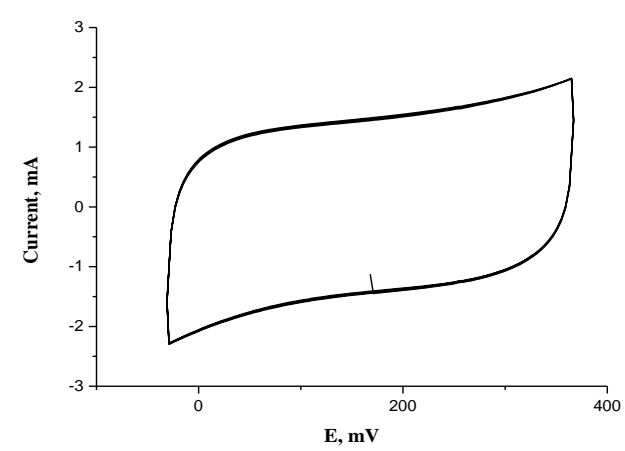

a

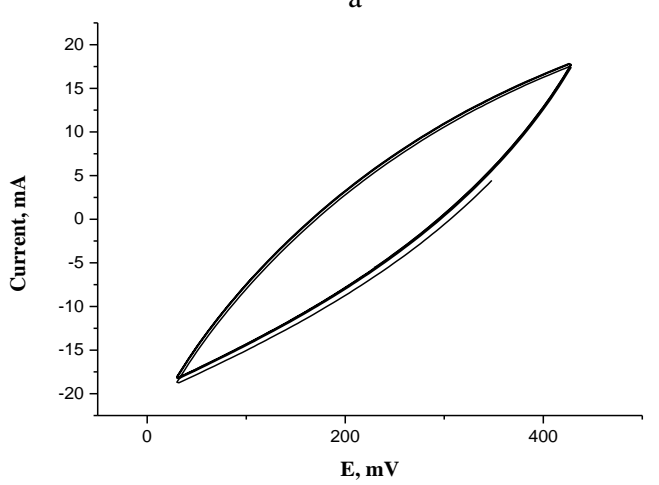

$\mathrm{b}$
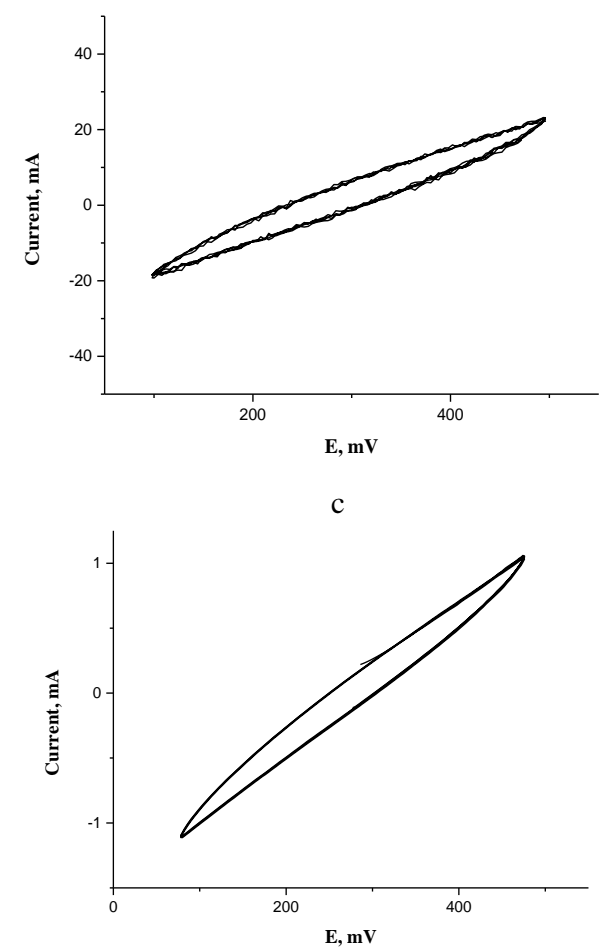

d

Fig. 5. The cyclic voltammetry curve of the carbon fiber electrode: $\mathrm{a}-$ untreated; $\mathrm{b}-2 \mathrm{~h}$ oxidation; $\mathrm{c}-4 \mathrm{~h}$ oxidation; $\mathrm{d}-6 \mathrm{~h}$ oxidation

With the increasing oxidation time, the defects increased, resulting in the increase of oxygen functional groups, the impedance of the electrode, and the enhanced resistance characteristics. Compared with CFEs-6, the resistive impedance of CFEs-4 maintained at a smaller level, 
which was supposed to be more conductive to obtaining a large and stable induced current and had a higher sensitivity to electric field measurement.

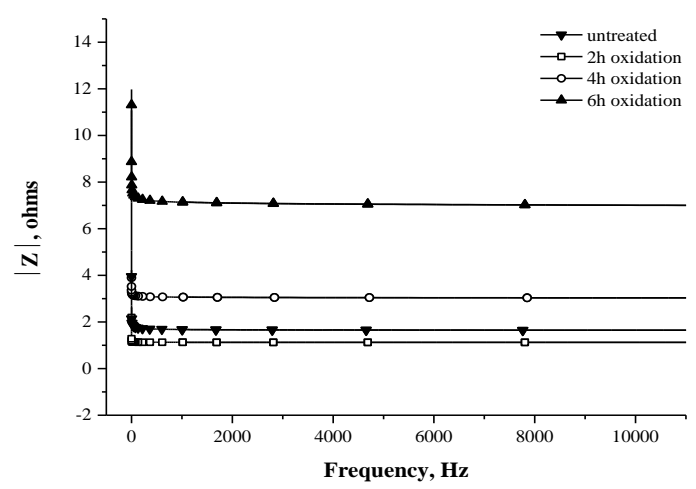

a

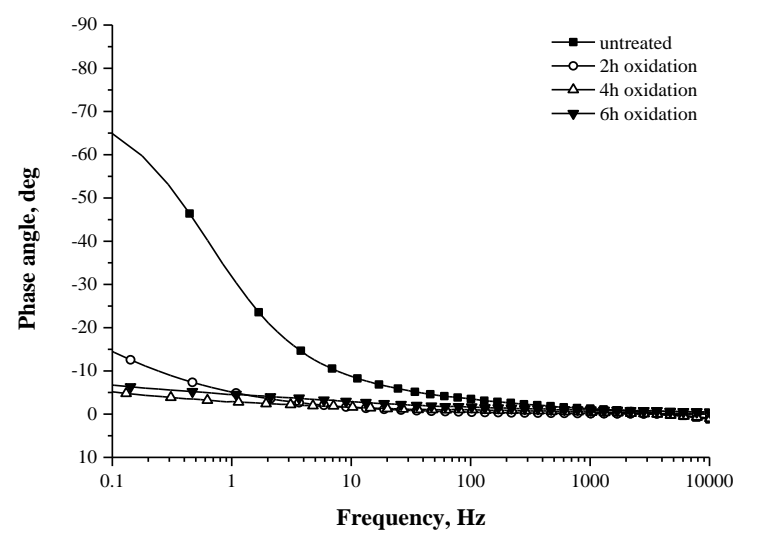

$\mathrm{b}$

Fig. 6. The EIS Bode curves of carbon fiber electrodes: a-the resistive impedance curve of electrodes; $b$-the phase frequency characteristic curve of electrodes

Fig. $6 \mathrm{~b}$ is the phase frequency characteristic curve of carbon fiber electrodes. In combination with the phase angle characteristics of pure resistance and pure capacitance, it is obvious that all electrodes show resistance characteristics when the disturbing frequency higher than $100 \mathrm{~Hz}$. With the decrease of frequency, the untreated carbon fiber electrode showed capacitive characteristics, while the phase angle of oxidized carbon fiber electrodes changed little, showing a good electrical resistance characteristic.

The surface characteristics of the electrode can be simulated by a suitable equivalent circuit, and the component ratio of $\mathrm{RC}$ is determined by the electrode characteristics.

The Nyquist diagrams of oxidized carbon fiber electrodes or the untreated ones are analogous. Taking CFEs-6 as the example, as shown in Fig. 6, there is no arcs but a line segment in the complex plane impedance diagram, for electrodes are chemically inert in the sea water. Therefore, there is no Faraday impedance, the AC impedance equivalent circuit diagram includes only the ohmic impedance of the solution, the electrode itself, and the double layer capacitance of the electrode-solution interface. The simple RC series circuit can be used to fit the impedance. Considering the non-homogeneity of the electrode surface, constant phase element (QPE) is used to replace capacitive element. The impedance of the QPE can be written as:

$\mathrm{Z}=\frac{1}{Q(j \omega)^{n}}$

where $Q$ is QPE constant, $n$ the QPE power and $\omega$ is angular frequency.

The fitted results for the electrical parameters are listed in Table 3. The fitting errors are within $3 \%$. QPE power $(n)$ has been often used to reflect the heterogeneity or porosity of rough electrodes $[12,13]$. The closer the $n$ is to 1 , the closer the system is to the ideal capacitance, on the contrary, it shows that the characteristics of electrode surface contribute to the impedance. With the oxidations strengthened, $n$ decreased, it meant the electrode capacitance decreased, and resistive properties enhanced for the diversification in the surface characteristics initiated by oxygen-containing groups.

Table. 3. The EIS fitting results of carbon fiber electrodes

\begin{tabular}{|c|c|c|c|}
\hline & $\mathrm{R}, \Omega$ & $\mathrm{QPE}-\mathrm{Q}, \Omega^{-1} \mathrm{~S}^{\mathrm{n}}$ & $\mathrm{QPE}-\mathrm{n}$ \\
\hline Untreated & 1.718 & 0.00733 & 0.73293 \\
\hline CFEs-2 & 1.146 & 5.684 & 0.55116 \\
\hline CFEs-4 & 3.029 & 4.326 & 0.29996 \\
\hline CFEs-6 & 6.840 & 0.01759 & 0.25051 \\
\hline
\end{tabular}

The results of polarization, cyclic voltammetry and EIS are consistent to illustrate the oxygen-containing groups will change electrodes from capacitive to resistive ones.

\subsection{The self-noise level}

After carbon fiber electrode pairs have been stable for $48 \mathrm{~h}$, the self-noise is measured by the ultra-low noise amplification measurement system. The result is shown in Fig. 7. The Table 4 lists the noise level.

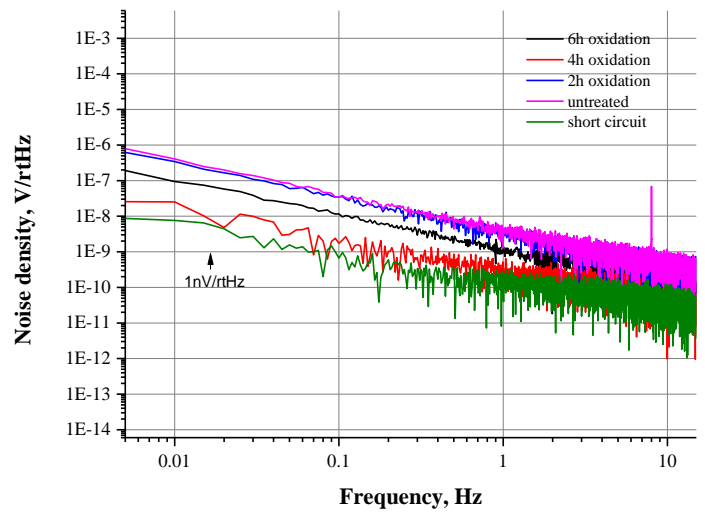

Fig. 7. The self-noise level of electrode pairs under different oxidation time

Table. 4. The self-noise performances of carbon fiber electrodes

\begin{tabular}{|c|c|}
\hline Oxidation time & Self-noise, $\mathrm{nV} / \sqrt{\mathrm{Hz}}$ \\
\hline $2 \mathrm{~h}$ & 6 \\
\hline $4 \mathrm{~h}$ & 0.9 \\
\hline $6 \mathrm{~h}$ & 2 \\
\hline Untreated & 7 \\
\hline
\end{tabular}

CFEs-4 showed better self-noise performance, the selfnoise voltage density at $1 \mathrm{~Hz}$ of electrode system is $0.9 \mathrm{nV} / \sqrt{\mathrm{Hz}}$, while commercial marine electric field sensors 
are generally lower than $2 \mathrm{nV} / \sqrt{\mathrm{Hz}}$ (following [14]), and the best can reach $0.5 \mathrm{nV} / \sqrt{\mathrm{Hz}}$ (Ultra-PMES). The suitable oxidation time of concentrated nitric acid can make the selfnoise reach a considerable level.

The noise of carbon fiber electrode decreases gradually with the oxidation, but when the oxidation degree further to $6 \mathrm{~h}$, the self-noise of carbon fiber electrode increases. At the initial stage of oxidation, the self-noise of the treated carbon fiber electrode decreased significantly compared with the untreated ones, which was a combined action of the impurity exfoliation and the polar functional groups. The former made the impurity charge sieve and the mobility of carriers reduce $[15,16]$. And the latter had stable adsorption with ions [17].

However, the carbon fiber surface will appear defect position due to oxidation of oxygen containing functional groups, which always has high adsorption energy. When the oxidation time reaches $6 \mathrm{~h}$, the fiber surface produced a large number of those adsorption sites, thus plenty of ions would in the dynamic adsorption and desorption process [17], greatly raising the self-noise of electrode.

\section{DISCUSSION}

\subsection{Oxidation processes}

Many attempts have been made to explore the mechanism of the liquid phase oxidation of carbon materials. As stressed by Alain et al. [18] , the wet oxidation includes three stages and $\mathrm{sp}^{2}$-type carbonaceous materials have similar reactions. It is expected that the oxidation starts with the initial oxygen on the surface, many oxygen groups would create on the surface. And in the next step, there is a transfer of oxygenated carbonaceous matter to the liquid phase. When the extent of oxidation increases, the process is stepping into the third stage, where the carboxylic groups created accompanying with the aromatic ring cleavages.

Concerning the experiment phenomena and results, the CFEs-2, CFEs-4, CFEs-6 corresponds to these three stages. With the prolonged oxidation time, the solution is getting pale brown. When the time reached 6 hours, the solution color turned black rather than brown. The exfoliation of the carbon fiber may give rise to such change, which are confirm to the cleavages in the third stage. The TGA and FTIR results prove this mechanism as well. CFEs- 6 has a lower decomposition temperature, then the CFEs-4 the CFEs-2 and the CFEs-0 are next, consecutively. Strong acidic groups decompose at a lower temperature and the weak acidic groups at a higher, thus CFEs-6 have more strong acidic groups created, which also confirmed in FTIR analysis.

\subsection{The relationship between oxidation processes and electrochemical performances}

Combined with the illustration in previous section, the electrochemical properties could be related to oxidation process to a certain extent.

With the increase of oxidation time, the carbon fiber became more resistive, which can be seen directly in both linear polarization and EIS results. Especially, the EIS result reflect more details of electrodes under different signal frequencies. When in higher frequencies, the polarization effect is weaker than in lower frequencies, for charges have no time to accumulate on the surface. Therefore, impedances under higher frequencies always keep a relative stable value.

Since polar functional groups on the carbon fiber surface can work as adsorption sites for physical adsorption, the electrode which have more such sites has a more stable surface-liquid phase. Impedances of resistive electrodes such as CFEs-4 and CFEs-6 change a lot with the frequency, reflecting in a much larger impedance under low frequency. The stable phase makes the surface more sensitive to different signal. Besides, electrodes pairs with more polar functional groups always take longer time to reach a stable electric potential differences. Thus, the impedance drop with frequency is relative to the time of a pair of electrodes to reach the stability.

The capacitive electrode such as CFEs-0 and CFEs-2 have a weaker surface-liquid phase, thus they are less sensitive to the signal change, with a small impedance change with frequency.

\section{CONCLUSIONS}

The electrode pairs prepared by $4 \mathrm{~h}$ oxidation in the concentrated nitric acid under $110^{\circ} \mathrm{C}$ have the best performance, which could reach a fast stability within 2 hours and keep a potential drift within $1 \mathrm{mV} / 24 \mathrm{~h}$. The long-term potential drift could decrease to $0.3 \mathrm{mV} / 24 \mathrm{~h}$ and the noise level is $0.9 \mathrm{nV} / \sqrt{\mathrm{Hz}} @ 1 \mathrm{~Hz}$.

The increase of oxygen containing functional groups on the surface, especially the limited increase in carboxyl group, is beneficial to increase the polarity and amend the inert of the carbon fiber, making its electric double layer formed closely with ions in the sea and obtaining a potential stability. However, the excessive increase of oxygencontaining functional groups would lead to a decrease of conductivity, a lowered detecting sensitivity with the increase of polarization resistance, as well as a prolonged time to establish stability.

\section{REFERENCES}

1. Crona, L., Fristedt, T., Lundberg, P., Sigray, P. Field Tests of a New Type of Graphite-Fiber Electrode for Measuring Motionally Induced Voltages Journal of Atmospheric \& Oceanic Technology 18 2010: pp. 92-99. https://doi.org/10.1175/15200426(2001)018<0092:FTOANT>2.0.CO;2

2. Cuervo, M.R., Asedegbega-Nieto, E., Díaz, E., Ordóñez, S., Vega, A., Dongil, A.B., Rodríguez-Ramos, I. Modification of the Adsorption Properties of High Surface Area Graphites by Oxygen Functional Groups Carbon 46 2008: pp. 2096-2106. https://doi.org/10.1016/j.carbon.2008.08.025

3. Pittman, C.U., B, Wu., Gardner, S.D., G.R, He. Chemical Modification of Carbon Fiber Surfaces by Nitric Acid Oxidation Followed by Reaction with Tetraethylenepentamine Carbon 35 (3) 1997: pp. $317-331$. https://doi.org/10.1016/S0008-6223(97)89608-X

4. Oda, H., Yamashita, A., Minoura, S., Okamoto, M., Morimoto, T. Modification of the Oxygen-Containing Functional Group on Activated Carbon Fiber in Electrodes of 
an Electric Double-layer Capacitor Sources 158 2006: pp. 1510-1516. https://doi.org/10.1016/j.jpowsour.2005.10.061

5. McCreery, R.L. Advanced Carbon Electrode Materials for Molecular Electrochemistry Chemical Reviews 108 (7) 2008: pp. 2646-2687. https://doi.org/10.1021/cr068076m

6. Zhou, J.H., Sui, Z.J., Zhu, J., Li, P., Chen, D., Dai, Y.C., Yuan, W.K. Characterization of Surface Oxygen Complexes on Carbon Nanofibers by TPD, XPS and FT-IR Carbon 45 2007: pp. $785-796$. https://doi.org/10.1016/j.carbon.2006.11.019

7. Zielke, U., Hüttinger, K.J., Hoffman, W.P. SurfaceOxidized Carbon Fibers: I. Surface Structure and Chemistry Carbon 34 (8) 1996: pp. 983-998. https://doi.org/10.1016/0008-6223(96)00032-2

8. Otake, Y., Jenkins, R.G. Characterization of OxygenContaining Surface Complexes Created on a Microporous Carbon by Air and Nitric Acid Treatment Carbon 31 (1) 1993: pp. $109-121$. https://doi.org/10.1016/0008-6223(93)90163-5

9. LU, W.B., Wang, C.G., Yuan, H., Hu, X.Y. Liquid-Phase Oxidation Modification of Carbon Fiber Surface The 2012 International Conference on Frontiers of Advanced Materials And Engineering Technology 2012: pp. 2008-2012. https://doi.org/10.4028/www.scientific.net/amr.430432.2008

10. Sezgin, S., Ates, M., Parlak, E.A., Sarac, A.S. Scan Rate Effect of 1-(4-methoxyphenyl)-1H-Pyrrole Electro-Coated on Carbon Fiber: Characterization via Cyclic Voltammetry, FTIR-ATR and Electrochemical Impedance Spectroscopy International Journal of Electrochemical Science 7 (2) 2012: pp. $1093-1106$. http://www.electrochemsci.org/papers/vol7/7021093.pdf

11. Li, N., Ma, X., Zha, Q., Kim, K., Chen, Y., Song, C. Maximizing the Number of Oxygen-Containing Functional Groups on Activated Carbon by Using Ammonium Persulfate and Improving the Temperature-programmed Desorption
Characterization of Carbon Surface Chemistry Carbon 49 2011: pp. 5002-5013. https://doi.org/10.1016/j.carbon.2011.07.015

12. Ye, Z.G., Meng, H.M., Sun, D.B. New Degradation Mechanism of $\mathrm{Ti} / \mathrm{IrO}_{2}+\mathrm{MnO}_{2}$ Anode for Oxygen Evolution in 0. $5 \mathrm{M} \mathrm{H}_{2} \mathrm{SO}_{4}$ Solution Electrochimica Acta 53 (18) 2008: pp. $5639-5643$. https://doi.org/10.1016/j.electacta.2008.03.025

13. Ye, Z.G., Meng, H.M., Sun, D.B. Electrochemical Impedance Spectroscopic (EIS) Investigation of the Oxygen Evolution Reaction Mechanism of $\mathrm{Ti} / \mathrm{IrO}_{2}+\mathrm{MnO}_{2}$ Anode for Oxygen Evolution in 0. $5 \mathrm{M} \mathrm{H}_{2} \mathrm{SO}_{4}$ Solution Journal of Electroanalytical Chemistry 621 (1) 2008: pp. 49-54. https://doi.org/ 10.1016/j.jelechem.2008.04.009

14. Slater, M., Schultz, A. Summary of Commercial Electromagnetic Field Sensors for the Marine Environment Oregon Wave Energy September (0905-00-012), 2010. https://doi.org/10.1175/15200426(2001)018<0092:FTOANT>2.0.CO;2

15. Du, J., Yue, R., Ren, F., Yao, Z., Jiang, F., Yang, P., Du, Y. Simultaneous Determination of Uric Acid and Dopamine Using a Carbon Fiber Electrode Modified by Layer-by-Layer Assembly of Graphene and Gold Nanoparticles Gold Bulletin 46 2013: pp. 137-144. https://doi.org/10.1007/s13404-013-0090-0

16. Xu, Y., Sheng, K., Li, C., Shi, G. Self-Assembled Graphene Hydrogel via a One-Step Hydrothermal Process Acs Nano 4 2010: pp. $4324-4330$. https://doi.org/10.1021/nn101187z

17. Ryoo, M.W., Seo, G. Improvement in Capacitive Deionization Function of Activated Carbon Cloth by Titania Modification Water Research 37 2003: pp. 1527-1534. https://doi.org/ 10.1016/s0043-1354(02)00531-6

18. Perrard, A., Retailleau, L., Berjoan, R., Joly, J.P. Liquid Phase Oxidation Kinetics of an Ex-Cellulose Activated Carbon Cloth by $\mathrm{NaOCl}$ Carbon 50 (6) 2012: pp. 2226-2234. https://doi.org/ 10.1016/j.carbon.2012.01.039 provided you give appropriate credit to the original author(s) and the source, provide a link to the Creative Commons license, and indicate if changes were made. 